\title{
VARIABILIDADE GENÉTICA E FLUXO GÊNICO EM POPULAÇÕES HÍBRIDAS E SILVESTRES DE PUPUNHA ACESSADA COM MARCADORES RAPD ${ }^{1}$
}

\author{
RONALDO PEREIRA SANTOS², MICHELLY DE CRISTO-ARAÚJO3, \\ DORIANE PICANÇO-RODRIGUES ${ }^{4}$, SPARTACO ASTOLFI FILHO ${ }^{5}$, CHARLES ROLAND CLEMENT $^{6}$
}

RESUMO - As populações híbridas de pupunha (Bactris gasipaes Kunth) acumularam variabilidade genética provenientes de raças primitivas ao seu redor, o que deveria aumentar sua variabilidade. Para testar esta hipótese, avaliou-se a variabilidade genética de populações híbridas por meio de marcadores RAPD utilizando 176 plantas mantidas no Banco Ativo de Germoplasma do INPA, Manaus-AM, sendo quatro populações híbridas [Belém $(\mathrm{n}=26)$; Manaus $(\mathrm{n}=38)$; Iquitos, Peru $(\mathrm{n}=41)$; Yurimáguas, Peru $(\mathrm{n}=41)$ ], duas populações silvestres (B. gasipaes variedade chichagui) tipos $1(\mathrm{n}=21)$ e $3(\mathrm{n}=7)$, e duas amostras de espécie afim, $B$. riparia, e compararam-se os parâmetros genéticos com estudos das raças primitivas. Oito iniciadores RAPD geraram 88 marcadores polimórficos e 11 monomórficos. O teste de replicabilidade apresentou uma similaridade de Dice 0,67 , considerado aceitável. A heterozigosidade média das populações híbridas foi 0,34 e o polimorfismo foi $87,9 \%$, maiores que nas silvestres $(0,31 ; 74,7 \%)$. O dendrograma das similaridades de Dice não apresentou grupos que representassem claramente as populações híbridas. O fluxo gênico entre Iquitos e Yurimáguas $(\mathrm{Nm}=12,75)$ e entre Iquitos e Manaus $(\mathrm{Nm}=9,47)$ foi alto, enquanto o fluxo entre Belém e Manaus $(\mathrm{Nm}=7,72)$ foi menor que o esperado, possivelmente devido à influência da raça Solimões. $\mathrm{O}$ alto valor de heterozigosidade em Manaus $(0,31)$ parece ser resultado da união de duas dispersões após a domesticação: a do oeste amazônico, com Iquitos e Yurimáguas, e a do leste amazônico, com Belém, que se juntam em Manaus. No entanto, essas populações não apresentaram acúmulo de variabilidade genética tão expressiva para diferenciá-las das raças primitivas.

Termos para indexação: Bactris gasipaes, variabilidade genética, fluxo gênico, similaridade de Dice, relações genéticas.

\section{GENETIC VARIABILITY AND GENE FLOW IN HYBRID AND WILD POPULATIONS OF PEACH PALM ACCESSED WITH RAPD MARKERS}

\begin{abstract}
The hybrid populations of peach palm (Bactris gasipaes Kunth) have accumulated genetic variability from adjacent landraces, which is expected to increase their variability. To test this hypothesis, 176 plants maintained in the peach palm Germplasm Bank at INPA, including four hybrid populations [Belém ( $\mathrm{n}=26)$; Manaus $(\mathrm{n}=38)$; Iquitos, Peru $(\mathrm{n}=41)$; Yurimáguas, Peru $(\mathrm{n}=41)$ ], two wild populations $(B$. gasipaes variety chichagui) types $1(\mathrm{n}=21)$ and $3(\mathrm{n}=7)$, and two samples of a related species, $B$. riparia, were genotyped with RAPD markers and compared to adjacent landraces reported in other studies. Eight RAPD primers generated 88 polymorphic and 11 monomorphic markers. The replicability test presented a Dice similarity of 0.67 , considered acceptable. The average heterozygosity of the hybrid populations was 0.34 and the polymorphism was $87.9 \%$, greater than in the wild populations $(0.31 ; 74.7 \%)$. The dendrogram of Dice similarities did not present groups that clearly correspond to the hybrid populations. The gene flow between Iquitos and Yurimáguas $(\mathrm{Nm}=12.75)$, and between Iquitos and Manaus $(\mathrm{Nm}=9.47)$ was high, while between Belém and Manaus it was lower than expected $(\mathrm{Nm}=7.72)$, probably due to the influence of the Solimões landrace near Manaus. The high value of heterozygosity in Manaus seems to be the result of the union of two dispersals after domestication: the western Amazonian dispersal, with Iquitos and Yurimáguas, and the eastern Amazonian, with Belém, joining in Manaus. However, these hybrid populations did not present an accumulation of genetic variability expressive enough to differentiate them from the landraces. Index terms: Bactris gasipaes, genetic variability, gene flow, Dice similarity, genetic relations.
\end{abstract}

\footnotetext{
'(Trabalho 193-10). Recebido em: 30-08-2010. Aceito para publicação em: 23-09-2011.

${ }^{2}$ Mestre, Instituto Nacional de Colonização e Reforma Agrária, Avenida André Araújo, 901 - Aleixo, Manaus, Amazonas, E-mail: ronaldo.santos@mns.incra.gov.br

${ }^{3}$ Mestre, Programa de Capacitação Institucional, Instituto Nacional de Pesquisas da Amazônia, Avenida André Araújo, 2396 - Aleixo, Manaus, Amazonas, E-mail: michelly_araujo@yahoo.com.br

${ }^{4}$ Doutora, Laboratório de Evolução Aplicada, Instituto de Ciências Biológicas, Universidade Federal do Amazonas, Avenida General Otávio Jordão Ramos, 3000 - Coroado, Manaus, Amazonas, E-mail: prdoriane@msn.com

${ }^{5}$ Doutor, Instituto de Ciências Biológicas, Universidade Federal do Amazonas, Avenida General Otávio Jordão Ramos, 3000 - Coroado, Manaus, Amazonas, E-mail: spartaco.biotec@gmail.com

${ }^{6}$ Doutor, Coordenação de Tecnologia e Inovação, Instituto Nacional de Pesquisas da Amazônia, Avenida André Araújo, 2396 - Aleixo, 69060-001 Manaus, Amazonas, autor para correspondência, E-mail: cclement@inpa.gov.br
} 


\section{INTRODUÇÃO}

A pupunha (Bactris gasipaes Kunth, Palmae) é uma fruteira nativa da Amazônia que apresenta ampla diversidade genética em suas populações silvestres e domesticadas, devido aos seus diferentes estágios de domesticação em diferentes ambientes e por atender a diferentes preferências humanas em termos de sabor, uso, processamento e até cor (CLEMENT, 1988; CLEMENT, 1995; MORA URPÍ et al., 1997). As populações de pupunha são agrupadas em duas variedades botânicas: Bactris gasipaes var. gasipaes, que inclui todas as populações domesticadas de pupunha com frutos grandes (15 a $200 \mathrm{~g}) ;$ B. gasipaes var. chichagui, que inclui todas as populações silvestres com frutos pequenos $(1$ a 15 g) (HENDERSON, 2000). Dentro de B. gasipaes var. gasipaes, as populações de pupunha são organizadas em raças primitivas (variedades locais ou crioulas, na terminologia da Embrapa) e populações híbridas modernas (MORA URPÍ; CLEMENT, 1988; MORA URPÍ et al., 1997).

Populações híbridas são centros modernos que acumulam variabilidade genética proveniente das raças primitivas ao seu redor (MORA URPÍ; CLEMENT, 1988). Como consequência, deveriam apresentar maior variabilidade e maior heterozigosidade que uma raça primitiva, por mais variável que essa seja. Enquanto qualquer raça é dinâmica em termos de sua composição, devido à introgressão contínua de nova variabilidade (LOUETTE, 2000), uma população híbrida poderia ser altamente dinâmica devido à introdução constante de grandes quantidades de nova variabilidade genética de raças divergentes ao seu redor. A hibridização de germoplasma divergente resulta numa 'explosão' de variabilidade devida à combinação de alelos diferentes (HARLAN, 1992).

Mora Urpí e Clement (1988) propuseram a existência de, pelo menos, quatro populações híbridas modernas na Amazônia, todas relacionadas com centros urbanos importantes, onde populações humanas têm acumulado considerável variabilidade genética de pupunha. Todas estas populações estão bem representadas no Banco Ativo de Germoplasma (BAG) de Pupunha, mantido pelo Instituto Nacional de Pesquisas da Amazônia em Manaus, Amazonas, Brasil (CLEMENT et al., 2001), e são:

1. Belém (Pará): esta população híbrida é constituída principalmente pela raça primitiva Pará, sendo distribuída na Amazônia Oriental até abaixo de Coari, Amazonas, nos trechos inferiores dos tributários da calha principal do Rio Amazonas e ao longo do Rio Madeira. Tem alguma influência da raça Solimões, a qual está distribuída ao longo do
Rio Solimões entre Coari e Fonte Boa, Amazonas, e da raça Putumayo, que está distribuída de Fonte Boa até acima de Iquitos, Peru.

2. Manaus (Amazonas): esta população é constituída pela raça Pará, com muita influência das raças Solimões e Putumayo, e provável influência das populações e raças do Rio Negro.

3. Iquitos (Loreto, Peru): esta população é constituída pela raça Putumayo, com influência das raças Solimões, Tigre, distribuída ao longo do Rio Tigre no Peru, Pampa Hermosa, Pastaza, a qual está distribuída ao longo dos Andes de Equador, e de populações ao longo do baixo Rio Ucayali, no Peru.

4. Yurimáguas (Loreto, Peru): esta população é constituída pela raça Pampa Hermosa, com influência da raça Putumayo e possivelmente de outras populações locais ainda não descritas. Esta população é muito importante por ser fonte de recursos genéticos para a expansão do agronegócio de pupunha para palmito no Brasil (CLEMENT et al., 2001; FARIAS NETO et al., 2002).

Estudos recentes com marcadores moleculares avaliaram a variabilidade genética das raças primitivas de pupunha, bem como o fluxo gênico entre essas. Usando marcadores RAPD, as análises genéticas sugeriram que as raças Pará e Putumayo são válidas, enquanto a raça Solimões é parte da raça Putumayo (SOUSA et al., 2001). Outras análises validaram a existência de quatro raças primitivas (Pará, Pampa Hermosa, Putumayo e Utilis) das sete examinadas e sugeriram que outras três raças (Solimões, Tuíra e Guatuso) deveriam ser consideradas populações de duas das raças validadas (RODRIGUES et al., 2004). Recentemente, Cristo-Araújo et al. (2010) completaram as análises genéticas das populações silvestres e domesticadas presentes no BAG, confirmando relações detectadas em outros estudos.

Uma análise morfométrica sugere que a raça Solimões deveria ser mantida, mas com tamanho menor que originalmente proposta (IRIARTEMARTEL et al., 2003), o que ainda não foi testado com marcadores moleculares. As populações ao redor de Yurimáguas, Peru, foram consideradas uma única raça com base na análise de marcadores RAPD (SILVA et al., 2003), ao contrário da hipótese de Mora Urpí e Clement (1988) sobre a existência de outras raças naquela região, com base na observação de extensa variabilidade morfogenética. Usando AFLP, Adin et al. (2004) compararam a diversidade genética entre populações domesticadas ao longo dos Rios Paranapura e Cuiparillo (Yurimáguas, Peru) e observaram pouca divergência e alto fluxo gênico, reforçando a hipótese de que são populações da raça 
Pampa Hermosa.

O presente estudo teve como objetivo testar a hipótese de que populações híbridas de pupunha possuem maior variabilidade genética do que as raças primitivas, avaliando e comparando a variabilidade genética das quatro populações híbridas com as raças primitivas, bem como com duas populações silvestres e algumas plantas de $B$. riparia Mart., por meio de marcadores moleculares RAPDs.

\section{MATERIAL E MÉTODOS}

Foram utilizadas 176 plantas, sendo 146 plantas de populações domesticadas da var. gasipaes: as quatro populações híbridas [Belém $(\mathrm{n}=26)$; Manaus $(n=38)$; Iquitos $(n=41)$; Yurimáguas $(n=41)]$; 28 plantas de populações silvestres, var. chichagui, tipos $1(n=21)$ e $3(n=7)$, e duas amostras de $B$. riparia Martius, a espécie filogeneticamente mais próxima à pupunha (FERREIRA, 1999). Todas as amostras são provenientes de progênies de meio-irmãos mantidas no Banco Ativo de Germoplasma de Pupunha (BAG), localizado na BR 174, km 38, Manaus-AM, Brasil. A identificação exata de cada amostra (passaporte) está disponível com o responsável pelo BAG, o último autor.

O DNA foi extraído por meio de um kit de extração da Invitrogen, denominado Plant DNAzol, utilizando-se de $100 \mathrm{mg}$ do meristema apical de um estipe lateral e quantificado por meio de comparação com um marcador molecular padrão, em gel de agarose $0,8 \%$ corado com brometo de etídio. Os RAPDs foram obtidos conforme Williams et al. (1990), com modificações de Rodrigues et al. (2004). Cada reação de amplificação, em volume final de $30 \mu \mathrm{l}$, continha $10 \mathrm{ng}$ de DNA genômico $(5 \mathrm{ng} / \mu \mathrm{l}), 250 \mu \mathrm{M}$ de dNTP (2,5 mM), $3 \mathrm{mM}$ de $\mathrm{MgCl}_{2}$ (25 mM), $50 \mathrm{ng}$ do iniciador $(10 \mathrm{ng} / \mu \mathrm{l}), 2 \mathrm{U}$ de enzima Taq polimerase (CENBIOT/RS) e $3 \mu 1$ de Tampão 1X (Tris-HCl 200 mM $\mathrm{pH}=8,6 ; \mathrm{KCl} 500 \mathrm{mM}$ ). Oito iniciadores amplificaram marcadores RAPD: seis da Operon Technologies (OPA4, OPA5, OPA8, OPA9, OPA18, OPA20) e dois da Biosystems (FC13, F-919-3). As amostras foram amplificadas em Termociclador (Perkin Elmer 9600) com dois programas. Programa 1 (para F-919-3): 1 etapa de 2 min a $94^{\circ} \mathrm{C}, 40$ ciclos de $1 \min$ a $92^{\circ} \mathrm{C}, 1$ min a $36^{\circ} \mathrm{C}$ e $2 \min$ a $72^{\circ} \mathrm{C}$, mais 1 etapa de $3 \mathrm{~min}$ a $72^{\circ} \mathrm{C}$. Programa 2 (para os demais): 2 ciclos de $1 \mathrm{~min}$ a $94^{\circ} \mathrm{C}, 1 \mathrm{~min}$ a $36^{\circ} \mathrm{C}$ e $2 \min$ a $72^{\circ} \mathrm{C}$, e 33 ciclos de 10 sa $94^{\circ} \mathrm{C}, 20 \mathrm{~s} \mathrm{a} 40^{\circ} \mathrm{C}, 2 \min$ a $72^{\circ} \mathrm{C}$, mais 1 etapa de 5 min a $72^{\circ} \mathrm{C}$. A utilização de dois programas de amplificação deve-se ao fato de um iniciador ter melhor resolução com o programa 1 (RODRIGUES et al., 2004).
Após a amplificação, separaram-se os produtos da reação por eletroforese em gel de agarose a 1,5 \% em tampão TBE $10 \mathrm{X}$ a $120 \mathrm{~V}$ por 4 horas; em seguida, foram corados com brometo de etídio de $0,5 \mathrm{mg} / \mathrm{ml}$, visualizados em Stratagene Eagle Eye II e fotografados com papel termal para Processador Mitsubishi Copiadora - Modelo K65HM. Os géis continham 33 amostras de pupunha, uma amostracontrole (um acesso de pupunha escolhida ao acaso para ser o controle e presente em todos os géis) e dois marcadores de peso molecular (1 kb ladder) nas extremidades.

As bandas foram classificadas como intensas (1), médias (2), fracas (3) ou ausentes (0), baseando-se na resolução e grau de amplificação por meio da avaliação visual, como descrito por Grattapaglia (1997). Para avaliar a confiabilidade das interpretações, compararam-se as similaridades de Dice dos indivíduos-controle de todos os géis analisados, agrupando as intensidades de três formas distintas: somente a banda intensa (1) é considerada válida e as bandas médias (2) e fracas (3) são consideradas ausentes, junto com a banda ausente (0); as bandas intensas (1) e médias (2) são consideradas válidas, e as bandas fracas (3) são consideradas ausentes, junto com a banda ausente $(0)$; todas as bandas visíveis (1;2 e 3) são consideradas válidas versus a banda ausente ( 0 ). A combinação que teve a maior similaridade entre os indivíduos-controle foi utilizada (GRATTAPAGLIA, 1997; RODRIGUES et al., 2004), no caso a terceira alternativa. Apesar de sofrerem de problemas de replicabilidade e interpretação genética (FERREIRA; GRATTAPAGLIA, 1998), esses marcadores moleculares foram usados porque oferecem informação útil quando trabalhados com cuidado (NYBOM, 2004). E, além disso, foram os primeiros usados no BAG Pupunha, e a continuidade de seu uso garante a consistência de análise necessária para entender o conjunto dos recursos genéticos de pupunha.

A partir da matriz binária, foram estimados a heterozigosidade [assumindo ausência como recessivo (WEIR, 1996)], usando o critério de $\mathrm{Nei}$ (1972), e a porcentagem de polimorfismo para cada amostra, com o programa TFPGA (MILLER, 1997). Para avaliar a diversidade genética, foram estimados $\mathrm{H}_{\mathrm{T}}$ (diversidade gênica total), $\mathrm{H}_{\mathrm{S}}$ (diversidade gênica dentro de populações) e $\mathrm{G}_{\mathrm{ST}}$ (diversidade gênica entre populações), usando o critério de Hartl e Clark (1989), e o fluxo gênico foi calculado [ $\mathrm{Nm}=0.5$ (1$\mathrm{G}_{\mathrm{ST}} / \mathrm{G}_{\mathrm{ST}}$ )] a partir das estimativas de $\mathrm{G}_{\mathrm{ST}}$ (SLATKIN; BARTON, 1989), com o programa POPGEN versão 1.31 (YEH et al., 1999). Foi gerada uma matriz de similaridades de Dice entre as amostras, com o 
programa NTSYS-pc (ROHLF, 1990). As relações genéticas entre as populações foram avaliadas pela distância de Nei (1972) e foi gerado um dendrograma com o algoritmo UPGMA (média aritmética não ponderada), com o programa TFPGA (MILLER, 1997).

\section{RESULTADOS E DISCUSSÃO}

Os oito iniciadores geraram 99 produtos de amplificação úteis (bandas), sendo 88 polimórficos e 11 monomórficos. O teste de repetibilidade usado por Rodrigues et al. (2004) detectou uma similaridade de Dice de 0,67 entre as amostras-controle, usando bandas de todas as intensidades $(1=2=3$ versus 0 ). A heterozigosidade observada foi menor que a esperada para todas as amostras (Tabela 1).

As quatro populações híbridas apresentaram heterozigosidades observadas e percentagens de polimorfismo maiores que as silvestres (Tabela 1), embora o esperado fosse o contrário. A espécie afim (B. riparia) teve nível de diversidade genética mais baixo comparado às demais amostras, provavelmente devido ao pequeno número de plantas. Entre as populações híbridas, Manaus apresentou maior heterozigosidade. Ao contrário da heterozigosidade, a taxa de polimorfismo não variou muito entre as populações.

A análise de agrupamento baseada na identidade genética de Nei (Figura 1) revelou dois grupos nitidamente separados, um composto das populações híbridas e outro das silvestres e $B$. riparia. No conjunto das populações híbridas, Manaus foi localizado entre o grupo ocidental (Iquitos, Yurimáguas) e Belém. Dentro das populações silvestres, observou-se uma separação entre a var. chichagui e B. riparia.

O fluxo gênico geralmente seguiu o padrão das distâncias geográficas. As populações híbridas de Iquitos e Yurimáguas apresentaram maior fluxo gênico (Tabela 2). Também houve alto fluxo gênico entre Iquitos e Manaus. O fluxo entre Belém e Manaus foi menor que o esperado. O fluxo entre B. gasipaes e B. riparia foi muito pequeno, como esperado.

O dendrograma gerado a partir das similaridades de Dice conteve 18 grupos resolvidos (definidos por similaridades $\geq 0,84$ ) (Tabela 3 ) e 6 grupos mal resolvidos (não apresentados na Tabela 3 ), sem um padrão que representa as populações híbridas, o que de certa forma confirme a ideia de que são híbridos. Alguns grupos tiveram predominância de uma população híbrida, como grupos 2; 3 e 4, mas todas as populações apresentaram plantas em mais de um grupo, com a população de Belém sendo um exemplo extremo.

Rodrigues et al. (2004), Silva (2004) e Cristo-Araújo et al. (2010) obtiveram repetibilidades melhores com o mesmo método: 0,95, 0,96 e 0,86, respectivamente. Isto poderia ser devido a problemas com o DNA do próprio controle, pois as similaridades de Dice entre as outras plantas analisadas foram da mesma ordem de magnitude das encontradas por estes autores. Valores baixos de repetibilidade não são incomuns em estudos que usam RAPD, e não comprometem necessariamente os resultados e objetivos propostos em análises com RAPD (SKROCH; NIENHUIS, 1995). Assim, a repetibilidade obtida $(0,67)$ não deve influir criticamente nessa análise, que visa a caracterizar a variabilidade genética e as relações presentes apenas neste conjunto de plantas.

Com a mesma metodologia, Cristo-Araújo et al. (2010) obtiveram 124 bandas polimórficas e 8 bandas monomórficas, um número um pouco maior que o polimorfismo obtido por Silva (2004) (101 e 23 , respectivamente), Rodrigues et al. (2004) (97 e 16 , respectivamente) e o encontrado neste trabalho (88 e 11, respectivamente). Os parâmetros genéticos estimados aqui não foram muito diferentes destes autores.

Devido à introdução contínua de novo germoplasma em populações híbridas oriunda das raças a seu redor, esperava-se que a heterozigosidade e a percentagem de polimorfismo nas populações híbridas fossem maiores que nas raças analisadas por outros autores: Sousa et al. (2001), Rodrigues et al. (2004), Silva (2004) e Cristo Araújo et al. (2010) (Tabela 4). No entanto, isso não ocorreu. A população de Manaus recebe fluxo das raças Solimões e Putumayo, além de estar rodeada pela raça Pará, na sua parte ocidental, mas sua percentagem de polimorfismo foi menor que a encontrada por Silva (2004), Rodrigues et al. (2004) e Cristo-Araújo et al. (2010). No entanto, a heterozigosidade observada média foi maior. A heterozigosidade estimada para Yurimáguas (Tabela 4) por Silva et al. (2003) foi expressivamente maior do que de qualquer população individual; isso provavelmente aconteceu pelo fato de se tratar de um conjunto de quatro populações da região de Yurimáguas (Rio Paranapura, Rio Shanusi, Alto Rio Huallaga e Rio Cuiparillo; $n$ $=120)$.

Por outro lado, as populações híbridas apresentaram heterozigosidades observadas médias e percentagens de polimorfismo maiores que as populações silvestres (Tabela 1), embora o esperado fosse o contrário, já que as populações híbridas são domesticadas, o que tende a reduzir a variabilidade genética comparada às populações silvestres (DOE- 
BLEY, 1989). Rodrigues et al. (2004) observaram uma heterozigosidade menor $(0,27)$, porém com polimorfismo de $80,5 \%$, em duas populações de Bactris gasipaes var. chichagui tipo 1 . O estudo realizado por Silva (2004) revelou baixas heterozigosidades $(0,23)$ e percentagens de polimorfismo $(63 \%)$ das duas populações silvestres dos tipos 1 e 2 que analisou. É provável que os baixos valores sejam devido ao pequeno número de acessos, porém o número de plantas é suficiente, dada a alta taxa de cruzamento esperado em pupunha (RODRIGUES, 2007).

A estrutura geral do dendrograma das populações híbridas (Figura 1) foi similar ao do dendrograma das raças de Silva (2004), mostrando uma clara separação entre as populações cultivadas e as silvestres, o que sugere que as populações silvestres analisadas não participaram na domesticação da pupunha. Rodrigues et al. (2004) encontraram relações mais próximas com as populações silvestres, sugerindo que as populações silvestres do Acre e do baixo Rio Ucayali (Peru) poderiam estar envolvidas na origem das pupunhas cultivadas. Uma análise com marcadores mais precisos permitirá identificar as populações silvestres que participaram da domesticação da pupunha. Mesmo sendo próximas filogeneticamente (FERREIRA, 1999), a separação entre $B$. gasipaes e $B$. riparia pode ser explicada pela amplificação de loci diferentes em espécies diferentes, observada em iniciadores de RAPDs
(FERREIRA;GRATTAPAGLIA, 1998). No entanto, o pequeno número de plantas usadas também não permite muita precisão.

O fluxo gênico mais elevado entre as populações híbridas de Iquitos e Yurimáguas (Tabela 2) ocorreu certamente por serem constituídas por raças primitivas da mesma dispersão após a domesticação (vertente ocidental) e por estarem geograficamente mais próximas, como observado por Adin et al. (2004). Isso também explica a pequena distância de Nei, uma vez que a proximidade geográfica entre populações implica tendência de aumento no fluxo gênico (GREGORIUS, 1987; BOSSART; PROWELL, 1998). Rodrigues et al. (2004) também observaram alto fluxo entre as raças primitivas Putumayo, Solimões e Pará que cercam as populações de Manaus e Iquitos. Belém é constituída principalmente por raça de outra dispersão, a raça primitiva Pará (vertente oriental). E a população híbrida Manaus é o ponto de encontro dessas dispersões, compartilhando alelos diferentes provenientes das raças Solimões e Putumayo (MORA-URPÍ; CLEMENT, 1988), além de possuir muitos alelos da raça Pará. Isso explica o alto valor de heterozigosidade nessa população. Esperava-se que o fluxo gênico entre as populações de Belém e Manaus fosse maior, já que ambas compartilham a raça primitiva Pará, porém não ocorreu porque fluxo de Manaus com as raças Solimões e Putumayo foi superior.

TABELA 1 - Parâmetros genéticos estimados com marcadores RAPD do conjunto de Bactris gasipaes, das quatro populações híbridas, de duas populações silvestres (tipos 1 e 3 ) e de uma espécie afim (B. riparia).

\begin{tabular}{lcccc}
\hline & & Polimorfismo & \multicolumn{2}{c}{ Heterozigosidade } \\
\cline { 3 - 5 } População & $\mathbf{N}$ & $\mathbf{9 9 \%}$ & Observada & Esperada \\
\hline B. gasipaes & 174 & 88,9 & 0,365 & 0,366 \\
Pop. híbridas & 146 & 87,9 & 0,343 & 0,344 \\
Belém & 26 & 71,7 & 0,281 & 0,287 \\
Manaus & 38 & 74,7 & 0,313 & 0,317 \\
Iquitos & 41 & 75,8 & 0,294 & 0,298 \\
Yurimaguas & 41 & 69,7 & 0,282 & 0,286 \\
v. chichagui & 28 & 74,7 & 0,311 & 0,317 \\
Tipo 1 & 21 & 73,7 & 0,304 & 0,311 \\
Tipo 3 & 7 & 58,6 & 0,244 & 0,262 \\
B. riparia & 2 & 33,3 & 0,138 & 0,184 \\
\hline Total & 176 & & &
\end{tabular}


TABELA 2 - Fluxo gênico ( $\mathrm{Nm}=0.5(1$ - Gst)/Gst) estimado da análise genética usando marcadores RAPD entre as quatro populações híbridas (Belém, Manaus, Iquitos e Yurimáguas), duas populações silvestres (tipos 1 e 3) e uma espécie afim (B. riparia).

\begin{tabular}{lcccccc}
\hline & Belém & Manaus & Iquitos & Yurimáguas & chicha. 1 & chicha. 3 \\
\hline Manaus & 7,72 & - & & & & \\
Iquitos & 5,88 & 9,47 & - & & & \\
Yurimáguas & 4,25 & 6,88 & 12,75 & - & - & \\
chichagui 1 & 3,65 & 4,32 & 3,73 & 2,96 & 5,46 & - \\
chichagui 3 & 2,44 & 2,85 & 2,98 & 2,35 & 2,37 & 1,95 \\
B. riparia & 1,24 & 1,37 & 1,32 & 1,29 & \\
\hline
\end{tabular}

TABELA 3 - Grupos de similaridade de Dice, número de plantas no grupo (n), similaridade (sim.) ( $\geq 0,84)$, e o número de plantas em cada população híbrida, população silvestre (tipos 1 e 3 ) e duas amostras de B. riparia. As 9 plantas em grupos mal resolvidas não são incluídas.

\begin{tabular}{|c|c|c|c|c|c|c|c|c|c|}
\hline Grupo & $\mathrm{n}$ & Sim. & Belém & Manaus & Iquitos & Yuri & chich. 1 & chich. 3 & B. rip. \\
\hline 1 & 3 & 0,86 & & 2 & 1 & & & & \\
\hline 2 & 24 & 0,86 & 2 & 20 & & 2 & & & \\
\hline 3 & 31 & 0,86 & 2 & 4 & & 23 & 1 & 1 & \\
\hline 4 & 29 & 0,85 & 1 & & 28 & & & & \\
\hline 5 & 26 & 0,86 & 3 & 1 & 10 & 12 & & & \\
\hline 6 & 3 & 0,85 & & 2 & & 1 & & & \\
\hline 7 & 2 & 0,88 & & 2 & & & & & \\
\hline 8 & 3 & 0,84 & 1 & 1 & & 1 & & & \\
\hline 9 & 4 & 0,84 & & & 1 & & 3 & & \\
\hline 10 & 10 & 0,88 & 9 & 1 & & & & & \\
\hline 11 & 4 & 0,89 & 4 & & & & & & \\
\hline 12 & 2 & 0,86 & & 2 & & & & & \\
\hline 13 & 2 & 0,84 & & & & 2 & & & \\
\hline 14 & 9 & 0,84 & 1 & 1 & & & 6 & 1 & \\
\hline 15 & 8 & 0,84 & & & & & 6 & 1 & 1 \\
\hline 16 & 3 & 0,87 & 2 & & & & & 1 & \\
\hline 17 & 2 & 0,84 & & & & & 2 & & \\
\hline 18 & 2 & 0,85 & & & & & & 2 & \\
\hline Total & 167 & & 25 & 36 & 40 & 41 & 18 & 6 & 1 \\
\hline
\end{tabular}

TABELA 4 - Parâmetros genéticos estimados com marcadores RAPD por vários autores para as raças primitivas de pupunha (Bactris gasipaes) associadas às populações híbridas, para serem comparados com os parâmetros em Tabela 1.

\begin{tabular}{|c|c|c|c|c|}
\hline & & Polimorfismo & Heterozigosidade & \\
\hline Raças & $\mathbf{N}$ & $99 \%$ & Observada & Autores \\
\hline Pará & 27 & 78,7 & 0,25 & 1 \\
\hline Pará & 30 & 75,0 & 0,30 & 2 \\
\hline Pará & 30 & 75,2 & 0,24 & 3 \\
\hline Pará & 15 & 75,0 & 0,27 & 4 \\
\hline Solimões & 30 & 78,7 & 0,25 & 1 \\
\hline Solimões & 30 & 82,3 & 0,30 & 3 \\
\hline Solimões & 62 & 91,7 & 0,32 & 4 \\
\hline Putumayo & 24 & 78,7 & 0,24 & 1 \\
\hline Putumayo & 30 & 73,0 & 0,28 & 2 \\
\hline Putumayo & 30 & 77,0 & 0,27 & 3 \\
\hline Putumayo & 68 & 93,2 & 0,34 & 4 \\
\hline Pampa Hermosa & 30 & 73,0 & 0,28 & 2 \\
\hline Pampa Hermosa & 30 & 75,2 & 0,26 & 3 \\
\hline Pampa Hermosa & 153 & 93,2 & 0,34 & 4 \\
\hline Pampa Hermosa & 120 & 90,4 & 0,33 & 5 \\
\hline
\end{tabular}

1 - Souza et al. (2001); 2 - Silva (2004); 3. Rodrigues et al. (2004); 4. Cristo-Araújo et al. (2010); 5. Silva et al. (2003). 


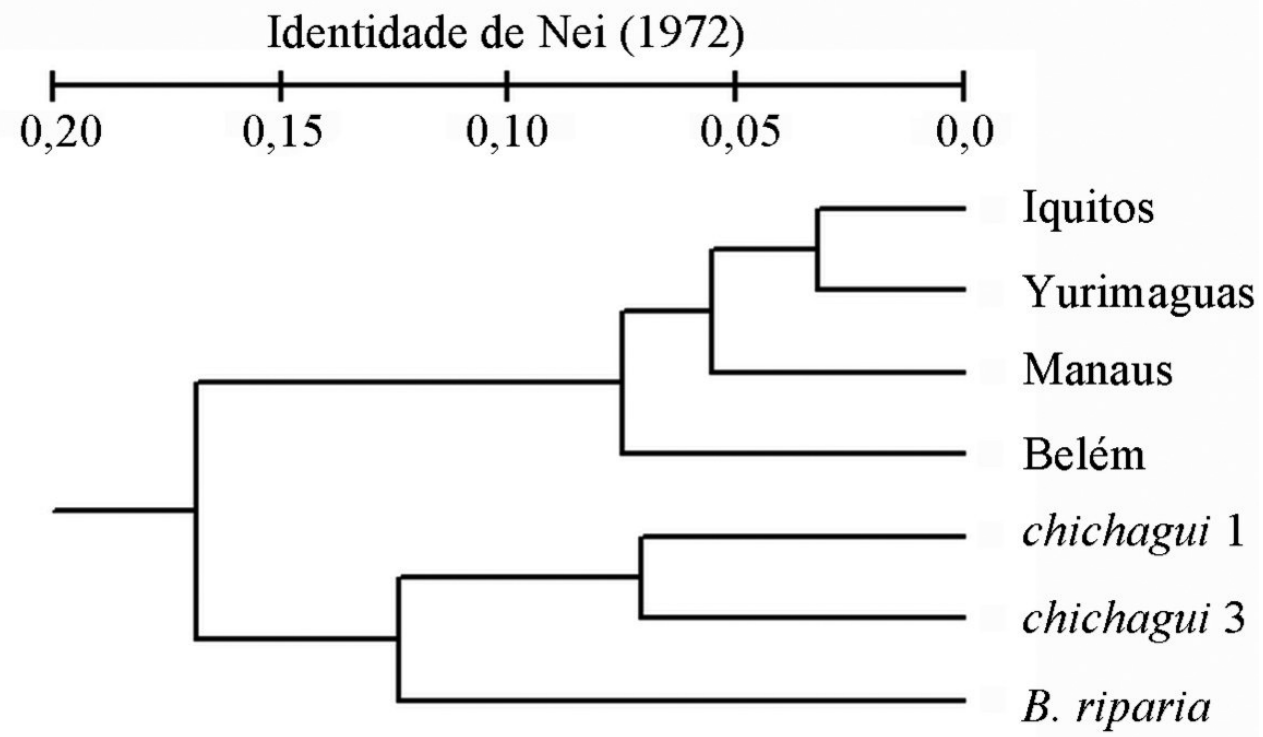

FIGURA 1 - Dendrograma UPGMA da identidade genética de Nei (1972), estimada a partir da análise genética usando marcadores RAPD, entre as quatro populações híbridas, duas populações silvestres (tipos 1 e 3 ) e uma espécie afim (B. riparia).

\section{CONCLUSÕES}

A hipótese de que as principais populações híbridas de pupunha na Amazônia apresentariam mais variabilidade genética do que as raças primitivas a seu redor não foi confirmada com as amostras disponíveis no Banco Ativo de Germoplasma e com os marcadores usados. Uma amostragem mais intensiva dentro das populações híbridas e o uso de marcadores codominantes poderiam permitir uma análise mais apropriada da hipótese.

\section{AGRADECIMENTOS}

Aos três revisores da RBF, que ofereceram críticas e sugestões importantes para melhorar a qualidade do artigo, ao CNPq Universal proc. no. 47.6189/2003-9 para o custeio, ao ProBio (MMA) - Pupunha: Raças primitivas e parentes silvestres (bolsa de RPS), à Fundação de Amparo à Pesquisa do Estado do Amazonas - FAPEAM (bolsa de MCA), e ao $\mathrm{CNPq}$ (bolsa de produtividade de SAF e CRC).

\section{REFERÊNCIAS}

ADIN, A.; WEBER, J.C.; SOTELO MONTES, C.; VIDAURRE, H.; VOSMAN, B.; SMULDERS, M.J.M. Genetic differentiation and trade among populations of peach palm (Bactris gasipaes Kunth) in the Peruvian Amazon - implications for genetic resource management. Theoretical and Applied Genetics, Berlin, v.108, p.1564-1573, 2004.

BOSSART, J.L.; PASHLEY PROWELL, D. Genetic estimates of population structure and gene flow: limitations, lessons, and new directions. Trends in Ecology and Evolution, London, v.13, n.5, p.202206, 1998 .

CLEMENT, C.R. Domestication of the pejibaye palm (Bactris gasipaes): past and present. In: BALICK, M.J. (Ed.). The palm - tree of life: biology, utilization and conservation. New York: The New York Botanical Garden,1988. v.6, p.155-174.

CLEMENT, C.R. Pejibaye (Bactris gasipaes). In: SMARTT, J.; SIMMONDS, N.W. (Ed.). Evolution of crop plants. $2^{\text {nd }}$ ed. London: Longman, 1995. p.383-388. 
CLEMENT, C.R.; YUYAMA, K.; CHÁVEZ FLORES, W.B. Recursos genéticos de pupunha. In: SOUSA, N.R.; SOUZA, A.G.C. (Ed.). Recursos fitogenéticos na Amazônia Ocidental: conservação, pesquisa e utilização. Manaus: Embrapa Amazônia Ocidental, 2001. p.143-187.

CRISTO-ARAÚJO,M; RODRIGUES, D.P.; ASTOLFI-FILHO, S.; CLEMENT, C.R. Genetic variability in the peach palm genebank with RAPD markers. Crop Breeding and Applied Biotechnology, Viçosa, MG,v.10, n.3, p.211-217, 2010.

DOEBLEY, J. Isozymic evidence and the evolution of crop plants. In: SOLTIS, D.E.; SOLTIS, P.S. (Ed.). Isozymes in plant biology. Oregon: Dioscorides Press, 1989. p.165-191.

FARIAS NETO, J.T.; YOKOMIZO, G.; BIANCHETTI, A.. Coeficientes de repetibilidade genética de caracteres em pupunheira. Revista Brasileira de Fruticultura, Jaboticabal, v.24, n.3, p.731-733, 2002.

FERREIRA, E. The phylogeny of pupunha (Bactris gasipaes Kunth, Palmae) and allied species. In: HENDERSON, A.; BORCHSENIUS, F. (Eds.). Evolution, variation and classification of palms. New York: New York Botanical Garden Press, 1999. v.83, p.225-236.

FERREIRA, M.E.; GRATTAPAGLIA, D. Introdução ao uso de marcadores moleculares em análise genética. Brasília: Embrapa - Cenargen, 1998. 220p.

GRATTAPAGLIA, D. Pseudo-testcross mapping strategy using RAPD markers. In: MICHELI, M. R.; BOVA, R. (Ed.). Fingerprinting methods based on arbitrarily primed PCR. Berlin: Springer Verlag, 1997. p.201-217.

GREGORIUS, H.R. The relationship between the concepts of genetic diversity and differentiation. Theoretical and Applied Genetics, Berlin, v.74, p.397-401, 1987.

HARLAN, J.R. Crops and man. $2^{\text {nd }}$ ed. Madison: American Society of Agronomy, Crop Science Society of America, 1992. 284p.
HARTL, D.L.; CLARK, A.G. Principles of population genetics. $2^{\text {nd }}$ ed. Massachusetts: Sinauer Associates, 1989. 542p.

HENDERSON, A. Bactris (Palmae). Flora Neotropica, New York, v.79, p.1-181, 2000.

IRIARTE-MARTEL, J.H.; FERRAUDO, A.S.; MÔRO, J.R.; PERECIN, D. Estatística multivariada na discriminação de raças amazônicas de pupunheiras (Bactris gasipaes Kunth) em Manaus (Brasil). Revista Brasileira de Fruticultura, Jaboticabal, v.25, n.1, p.115-118, 2003.

LOUETTE, D. Traditional management of seeds and genetic diversity: what is a landrace? In: BRUSH, S. B. (Ed.). Genes in the field: on-farm conservation of crop diversity. Florida: Lewis Publishers, 2000. p.109-142.

MILLER, M.P. Tools for population genetic analysys (TFPGA): a windows program for the analysis of allozyme and molecular population genetic data, version 1.3. Flagstaff: Northern Arizona University, 1997.

MORA URPÍ, J.; CLEMENT, C.R. Races and populations of peach palm found in the Amazon basin. In: CLEMENT, C.R.; CORADIN, L. (Ed.). Final report (revised): Peach palm (Bactris gasipaes H.B.K.) germplasm bank. Manaus: Instituto Nacional de Pesquisas da Amazônia/Centro Nacional de Recursos Genéticos, 1988. p.78-94.

MORA URPÍ, J.; WEBER, J.C.; CLEMENT, C.R. Peach palm. Bactris gasipaes Kunth. Promoting the conservation and the use of underutilized and neglected crops. Rome: Institute of Plant Genetics and Crop Plant Research, 1997. 83p.

NEI, M. Genetic distance between populations. American Naturalist, Chicago, v.106, p.283-292, 1972.

NYBOM, H. Comparison of different nuclear DNA markers for estimating intraspecific genetic diversity in plants. Molecular Ecology, Oxford, v.13, p.11431155, 2004. 
RODRIGUES, D.P. Diversidade genética e sistema de reprodução em progênies elites de pupunheira inerme (Bactris gasipaes Kunth) com marcadores microssatélites: Implicações para o melhoramento do palmito. 2007. 103 f. Tese (Doutorado) - Universidade Federal do Amazonas, Manaus, 2007.

RODRIGUES, D.P.; ASTOLFI-FILHO, S.; CLEMENT, C.R. Molecular marker-mediated validation of morphologically defined landraces of Pejibaye (Bactris gasipaes) and their phylogenetic relationships. Genetic Resources and Crop Evolution, Dordrecht, v.51, p.871-882, 2004.

ROHLF, F.J. NTSYS-PC: Numerical taxonomy and multivariate analysis system, version 1.6. Exeter. New York: Exeter publications, 1990.

SILVA, C.C. Análise molecular e validação de raças primitivas de pupunha (Bactris gasipaes) por meio de marcadores RAPD. 2004. 65 f. Dissertação (Mestrado) - Universidade Federal de São Carlos, São Carlos, 2004.

SILVA, C.C.; RODRIGUES, D.P.; ASTOLFI FILHO, S.; CLEMENT, C.R. Análise da variabilidade genética de pupunha (Bactris gasipaes) da região de Yurimáguas, Peru, por meio de marcadores moleculares RAPDs. Manaus: INPA, UFAM, 2003. 5p. (Relatório de Projeto)
SKROCH, P.; NIENHUIS, J. Impact of scoring error and reproducibility of RAPD data on RAPD-based estimates of genetic distance. Theoretical and Applied Genetics, Berlin, v.91, p.1086-1091, 1995.

SLATKIN, M.; BARTON, N.H. A comparison of three indirect methods for estimating average levels of gene flow. Evolution, Boulder, v.43, p.1349-1368, 1989.

SOUSA, N.R.; RODRIGUES, D.P.; CLEMENT, C.R.; NAGAO, E.O.; ASTOLFI-FILHO, S. Discriminação de raças primitivas de pupunha (Bactris gasipaes) na Amazônia brasileira por meio de marcadores moleculares (RAPDs). Acta Amazonica, Manaus, v.31, n.4, p.539-545, 2001.

WEIR, B.S. Genetic data analysis II: methods for discrete population genetic data. Sunderland: Sinauer Associates, 1996. 445p.

WILLIAMS, J.G.K.; KUBELIK, A.R.; LIVAK, K.J.; RAFALSKI, J.A.; TINGEY, S.V. DNA polymorphisms amplified by arbitrary primers are useful genetic markers. Nucleic Acids Research, Oxford, v.18, p.6531-6535, 1990 .

YEH, F.C.; YANG, R-C.; BOYLE, T. Microsoft windows-based freeware for population genetic analysis, POPGEN, v. 1.31. Edmonton: University of Alberta and Center for International Forestry Research, 1999. 